\title{
Primo Vascular System: Before the Past, Bizarre Present and Peek After the Future
}

\author{
Miroslav Stefanov* \\ Department of Morphology, Physiology and Nutrition, Agricultural Faculty, Trakia University, Stara Zagora, Bulgaria
}

Received August 13, 2021

Revised October 27, 2021

Accepted December 6, 2021

Correspondence to

Miroslav Stefanov

Department of Morphology, Physiology

and Nutrition, Agricultural Faculty,

Trakia University, Stara Zagora,

Bulgaria

E-mail stefanov.miroslav.g@gmail.com
Introduction: Is Primo Vascular System (PVS) a paradox? Finding the connection between PVS as a carrier of information and the body's reactions at the micro and macro levels will be the starting point in understanding the meaning of life as such.

Before the past of PVS knowledge: The initial phase of medicine in all cultures is reduced to the transfer of specific energy by special pathways throughout the body! This is the case in China, India, Japan, Korea, Tibet, etc. Undoubtedly, the five articles by B. H. Kim published in the early 1960s are considered to be the past of PVS.

Strange present: PVS studies after 2002 are accepted as a present. Most of the articles on the topic are in journals with editors-in-chief originating and/or accepting the achievements of Eastern medicine. Is the science of PVS local since its research is in journals that publish mainly articles on Eastern medicine? Why few of the articles concerning PVS are in Western medicine journals?

PVS: after the future or some conclusions and proposals: All substances, objects, biological objects generate a weak electromagnetic radiation typical for each of them which is a passport of the information. PVS has all the data to be the main carrier of information. Information medicine and Quantum Biology can serve as a basis for medicine and biomedical sciences, and it should explain the processes that exist for the change of DNA and organisms in general, in accordance with and in response to external causes and internal changes.

Keywords: PVS, History, Future, Quantum biology, Information medicine

\section{INTRODUCTION}

Is Primo Vascular System (PVS) a paradox? Is PVS a phenomenon? Is PVS a myth? Is PVS a beautiful lie, only fruit of our imagination?

This is the essence of the questions that are often asked by critics [1-3]. More embarrassingly, critics provide no evidence of their doubts. Their doubts are based solely on the lack of trust in the achievements of the PVS community. In fact, the persons who criticize that the PVS community does not use reliable and convincing scientific methods themselves do not offer scientific arguments and evidence but only their belief that PVS does not exist. In response, the PVS community offers not only a belief in the existence of PVS, not only faith in the exceptional functions of PVS but also systematic scientific evidence as a result of depth studies made by modern and repeatable scientific methods according to strict scientific protocols.

Why do we do science? Because only science provides both specific evidence and philosophical explanations regarding the nature of things around us and within us. Because only scientists can objectively evaluate the present, explain the past and look far into the future without fantasizing.

Therefore, my intention at this paper is to present the topic of PVS synthetically. Synthetically, because there is already a lot of accumulated analytical data concerning PVS. On the other hand, it is time for more articles answering philosophical questions to appear: How and Why PVS Exists and Works.

It is time to establish a branch in the study and presentation of PVS to be called "Philosophy of PVS". The study and dissemination of knowledge biomedical sciences, which will provide the basis for a new era in research on living organisms and life in general as a phenomenon.

It is PVS that is the appropriate basis to answer the basic philosophical question: What is primary - matter or energy?

In fact, matter and energy turning into each other are the possible two sides of the same phenomenon - Life! 
Analyzing the specific characteristics of PVS has a fundamental chance to provide answers to the deepest questions of humanity. Finding the connection between PVS as a carrier of information existing inside and outside organisms and the body's reactions at the micro and macro levels, through physiological and pathological changes, will be the starting point in understanding the meaning of life as such.

PVS is currently so far removed from the current possibilities of science that "orthodox" scientists cannot see it and simply cannot perceive it and therefore refuse to see and accept it.

I have set two goals at this paper.

First. I will consider the topic as a historian of PVS, as a commentator on current developments in our field, and as a forecaster of the possibilities and limits of the topic in the future.

Second. Finally, I will try to give my opinion on which to step in order to place the topic as one of the main in the development of biology and biomedical sciences.

The starting points will be the knowledge of the peoples and cultures that existed before the idea of PVS, as well as scientists who have revived and expanded the topic of PVS in our time, and I will try to intertwine the achievements of other sciences to give space for the development of knowledge and achievements concerning PVS, the basis of the new paradigm of sciences of Life.

\section{BEFORE THE PAST OF PVS KNOWLEDGE}

The initial phase of medicine in all cultures is reduced to the transfer of specific energy by special pathways throughout the body! This is the case in China, India, Japan, Korea, and Tibet. Whether the pathways will be called sen, meridians, channels, vessels or Nadis, the essence of the matter is the transfer of vital life force, prana or chi which accomplishes healing purposes of body and soul. The specific energy on which life is based is characterized as an energy flow of bio-electrical, resonant, or vibrational nature. Over 3000 years ago, different ancient cultures and philosophies have described sophisticated networks of pathways, channels, sen and/or nadis where vital energy and/or life force energy flows. Why the meridian theory has originated only in ancient China, adopted in the $5^{\text {th }}$ or $6^{\text {th }}$ century by Japan and Korea, and in the $8^{\text {th }}$ or $9^{\text {th }}$ century by Vietnam, although there are facts about the presence of similar meridians in humans and in other latitudes [4]? For example, in Europe, the famous Ice Man Ötzi existed 3000 years before the emergence of the Meridian Theory in China [5]. Their tattoos are almost identical to the acupuncture points in the Chinese medicine. Prehistoric tattooed mummies have been found in Siberia, Peru, Chile, and Africa [6]. Tattoos are similar to the acupuncture points in the classical Chinese medicine, and it is speculated that they are a medical system close to acupuncture. Histological examinations of their tattooed points indicate that they probably have therapeutic purpose. Permanent tattoos serve both as a long-term form of diseases treatment and also as a marker to be used by non-specialists. All these data show that acupuncture may have originated elsewhere 2000 or 3000 years before what we know about Traditional Chinese Medicine, which is considered to have originated in $1000 \mathrm{BC}$. Therefore, some authors consider that acupuncture has more Euro-Asian than East Asian origins.

In Europe, acupuncture was first used in the $13^{\text {th }}$ century. In 1938, Soviet scientists proved that there were lines and points on the surface of the skin with increased electrical conductivity which persists for 10 or 12 hours postmortem. In 1952, the Soviet school introduced the term "Biologically Active Point" (BAP). The location of BAP on the surface of the skin completely coincides with the acupuncture points known from ancient Chinese sources [7]. In 1958, Niboyet and Mery [8] proved that meridians objectively exist, and their properties are preserved even after death, even on a dismembered corpse. The question is "Why ancient Eurasian, South American, or African medicine has not originated from these acupuncture points of tattooed human mummies in these geographic regions, or based on BAP in Europe, but only in East Asia?" The answer to this question probably lies in the different culture that existed at that time which gave rise to different philosophies looking at and explaining the world around us. For this reason, in ancient China conditions were created for the emergence of Taoism, Confucianism, and Holism. Different ethical systems have been formed. The individual in ancient China is associated with the supernatural, and their healers have supernatural abilities.

Since the Chinese medicine emerged from different ethical systems and philosophical views, perhaps we should now try to lay the foundation for a new, modern philosophical worldview explaining the theory and practice of the Meridian System. The efforts of scientists dedicated to PVS should be aimed both at discovering new data on PVS, as well as at confirming what has already been found on the subject. In addition, it would be useful to make a new effort - to give a philosophical explanation of the existing knowledge about PVS. In view of this, the use of hermeneutica would be useful. Interpretation of current data implies not only knowledge of PVS but also the context in which it exists. The place, the participants, the time in which the knowledge about PVS has developed must be taken into account. Thus, through hermeneutica, some boundaries will be crossed, not in order to erase them, but in order to combine them into a new knowledge. For this reason, I will give an example of a similar approach in an attempt to re-read what is already known 
from the past.

Undoubtedly, the five articles by B. H. Kim [9-12] published in the early 1960s are considered to be the past of PVS. The data in these articles are defined as the main basis on which to step in order to build on what was left by B. H. Kim [13]. In this sense, I will present some of my comments on these articles in view of modern knowledge, as well as my understanding of it. My comments are described in detail in the article "Critical review and comments on B. H. Kim's work on the PVS" [14].

In summary, my opinion concerning BH Kim's papers is:

The PVS integrates the cardiovascular, the nervous, and the hormonal systems. Thus, the particularities of different body systems are combined in the PVS.

The PVS is not a simple circulatory system like the cardiovascular system.

Its influence on the whole body is a combination of not only substances and signals but also energy and information.

The primordial PVS is like a matrix for the vascular and the nervous systems, which are formed around the PVS. The PVS is duplicated by the vascular and the nervous systems in the very early stage of body development. This is the reason why the PVS combines the features of the vascular, the nervous, and the hormonal systems. Subsequently, after all embryonic body systems have been developed, the primordial PVS remains connected with them, but dominates and controls them as the oldest morphological functional system.

\section{STRANGE PRESENT}

PVS studies after 2002 are accepted as a present. Most of the articles on the topic are in journals with editors-in-chief originating and/or accepting the achievements of Eastern medicine. Is the science of PVS local since its research is in journals that publish mainly articles on Eastern medicine? Why few of the articles concerning PVS in magazines editors originating and supporting Western medicine considered being modern and authoritative currently?

Modern science versus ancient science. Western medicine versus Eastern medicine [15]. Are these the questions? Is this a battle? Is this the real battle? It is strange to ask such questions, but this is how I see the problem of disseminating knowledge about PVS at the moment. The cessation of science was characteristic of the dark times of the Middle Ages, and that is why the current state of PVS science seems strange to me.

At present, we know that with the advancement of knowledge and technology in medical science, questions that cannot be answered are growing. Modern science cannot answer the newly emerging questions for many reasons. It is an intrusive fact that the ancient medicine on which Eastern medicine is based has existed successfully for thousands of years. Initially, we find it as an independent form of medicine, and later shared its existence in parallel with the development of other branches of medicine, including the current form of Western medicine. Many of the various forms of medicine are now only in history, such as medicine from Mesopotamia, Egypt, India, Galen's medicine, which ruled for 1500 years, etc. Meridian theory and practice existed in their time and continues to exist today [16].

The question is: If there is no rational moment in Ancient Medicine based on the Meridian Theory, if it has no healing properties, then how has it not disappeared like the ones already mentioned but it continues to exist for millennia? Is it a prejudice to be based on an outdated and lacking scientific basis for the medicine for which Eastern medicine is presented, or is it a prejudice not to accept it because we do not fully understand the mechanisms of its work?

Acupuncture was used as early as the late Stone Age but it did not enter modern Western medicine until the 1970's when China ended a period of isolation. Thus, we have only 50 years of real contact in the modern ages between Eastern and Western medicine as a whole. One of the reasons the range of understanding of Meridian system has grown slowly in the West is possibly because of the belief that it has no anatomical and scientific basis.

But, very strangely, when many scientific teams from different laboratories, universities, countries and from different continents [17-79], using strictly scientific methods and protocols, prove the presence of anatomical basis of the Meridian System, clearly showing the physiological pathways ensuring the health effect of Eastern medicine, the leading scientific journals, dominated in their editorial boards by scholars of Western medicine, refuse to publish them. They reject such articles without even reviewing them, without the debate that underlies science at all. Strangely why!?

Truth should be told!

Is the science of PVS a pseudoscience that the articles on this topic are often rejected? In pseudoscience there are no facts established by objective methods or there is no theory for the respective scientific object. For PVS there are many facts established by strict scientific protocols and methods, there is a general theory of its existence based on the presence of an anatomical basis and determined functional capabilities. Thus, Eastern medicine based on the Meridian Theory has no reason to be defined as pseudoscience and there is no reason why articles on the subject should not be peer-reviewed and published in Western journals.

We say that PVS is "hidden" in the accompanying tissues. This is true. But, I think, we should also comment on the fact that the world scientific community is "hiding" from recognizing the existence of PVS. Even worse, modern Wes- 
tern science, occupying the highest positions in scientific periodicals, "hides" the existence of PVS. Many medical and biology journals refuse to accept articles related to PVS. Some colleagues, in order to publish their data about PVS, have used the indifferent term "fibrous or threadlike structures" instead of PVS. But knowledge and achievement can be slowed down, but they cannot be stopped.

PVS has unique morphological features and physiological characteristics [17-79]. The question is how to activate and control the various sections and parts of PVS. In fact, the meridians and acupuncture points are the map that shows the places of impact on the PVS, without directly reaching its system of vessels and nodes. If you want to reach the circulatory system, you puncture a blood vessel. If you want to activate PVS, you activate the acupuncture points in a certain area. There is no doubt that PVS is a new vascular system other than the circulatory and lymphatic systems. But is PVS the only vascular system? The vascular systems in the high classes of animals are of closed type. The bloodstream has two circles through which the blood moves constantly. The lymphatic system is also closed, but begins blindly in the interstitial spaces and it flows only in the direction of the heart. Both systems have their supporting vessels and basic anatomical organs: for the blood - heart with pericardium and spleen, and for the lymph - lymph nodes. Obviously, both the circulatory and lymphatic systems have their own vessels, which independently carry the corresponding fluid - blood and lymph throughout the body. PVS, although it is defined as the vascular system, as evidenced by its name, has its peculiarities. The vessels of PVS go in several numbers wrapped in a common envelope. Multivascular fibrous formations carry a specific fluid containing a number of building elements needed by the body, as well as sanal cells - specific cells with a size of 1-2 $\mu \mathrm{m}$, containing 1-2 chromosomes. The multivascular vessels (PVs) of PVS do not have their own channel, but they accompany the vessels of the circulatory and lymphatic systems being located both on their surface and also floating in the flow of blood or lymph. In addition on/in the vessels, PVs are located in the perineurium of the nerves and accompany them to the central nervous system. There are nodes in PVS that represent specific extensions. Apart from our proposal published in JAMS $[48,49]$, there are no other authors to report which are the central organs of PVS, as soon as PVS is claimed to be a separate anatomical system. In our publications, we have pointed out that, from an anatomical point of view, PVS does not have a single and constant cycle of movement of its fluid, but there are different cycles of movement that serve different groups of organs. The description of the different anatomical circles of PVS, along which the respective cycles of movement of PVS fluid take place, has given me reason to propose different main organs for the different subsystems of PVS. The heart is the organ that occupies a central place in the vascular part of the system, and the brain is the central organ in the nervous cycle of PVS, as the nerves lead PVs to the central organs of the nervous system - spinal cord and cerebrum. Due to the lack of connective tissue in the central organs of the nervous system, PVs (primo vessels) also reach it through their blood vessels. On the other hand, the nodes (primo nodes, PNs) of PVS are not only a place where there are different building elements, but also act as "control centers" for connection between the different levels and subsystems of PVS. PNs are the place where PVS can close and open depending on external and internal stimuli. The ability of PVS to have open and closed cycles and levels allows the system to have parts that are at rest as well as active parts. In fact, the resting phase does not mean that PVS does not function in this area. On the contrary, I consider that it is in this phase that it is possible to restore damaged parts with the building elements supplied by the PVS fluid, as well as the information provided about the limits of the need to "repair and restore" a certain anatomical area, whole organ or a whole group of organs. The triggering of the active phase serves only to bring the necessary information and spare substances to the target area in order to restore or regenerate it.

Doubts whether PVS is the real and the only anatomical basis of meridians comes from two directions.

First. No distinct anatomical connection was found between the acupuncture points and any of the parts of PVS.

Second. The distribution of the individual parts and cycles of PVS does not coincide with the positions of the meridians.

To verify these doubts, we researched and published some data regarding this subject [27]. The experiment we conducted was performed as per the following design. We injected a different colored liquid polymer into the acupuncture points of recently mortified mice. The use of the polymer is to visualize the possible pathways that are triggered by an external signal (for example acupuncture needle pricking). We used this polymer because it is proven that it crosses the capillary barrier of the circulatory and lymphatic systems, even between endothelial cells, which makes it convenient and sufficient to conduct the study. After a certain period of time, the polymer hardened, during which we subjected the mice to partial maceration. During maceration, the passage of the polymer through the tissues became visible and it became possible to trace it along its entire length. To control the experiment, other mice were injected into non-acupuncture points with a colorless polymer. The results showed that we can trace the polymer from the injection place at the acupuncture points to the surface of the organ. The surprise turned out to be in two directions. First, the polymer passes 
from acupoints to the authorities but not in the way of known meridians. Second, particles of colored polymers were found inside the organs with no visible connection to the surface of the organ. The polymer injected at the non-acupuncture points did not spread and remained at the injection place. The conclusions that can be drawn are that even in dead animals, somehow, the polymer reaches the surface of the organs and there, surprisingly and strangely, passes through the capsule of the organs without a visible trace, after which we found it inside them. The experiment shows that the tissues retain their permeability even for the polymer, even after the death of the animal $[27,51,52]$. The presence of increased electrical conductivity in acupuncture points observed after death in humans and even a dismembered corpse was reported as early as 1938 by Soviet scientists [7], confirmed in 1958 by Niboyet and Mery [8]. The "behavior" of the polymer absolutely repeats the action of a needle puncture at an acupuncture point. Our opinion is formed by the different distribution of the polymer in test and control animals. The signal (respectively the polymer) passes from the acupuncture point to the inside of the organ, while when injected into nonacupoints it remains at the site of its introduction. The results covered various internal organs, glands, spinal cord [27,52], which allows us to speculate that the polymer has passed through different levels and circles of PVS. What confuses us to unambiguously accept PVS as the anatomical basis of the Meridian Theory is that the course of the polymer, although it reaches from an acupuncture point to an organ, does not follow the known meridians. We can offer two options for explaining this phenomenon. First. The meridians are only channels for the passage of energy which does not oblige them to have a strict anatomical basis but to "jump" through the tissues. There is such an example in organisms. The sinoatrial node of the heart has no anatomical connection with the atrioventricular node, but the signal "jumps" from the first to the second and thus the autonomic innervation of the heart is carried out, as well as its constant work. Of course, the nature of the signal in the heart and acupoints is very different and serves only as an illustration. The impact on the acupuncture points can have two aspects. On the one hand, the physical signal leads to its passage through the pathways shown by the liquid polymer, and on the other hand the energy/information moves by "jumping" in the way described in the heart, without the need for an anatomical connection and a special organ. Second. In the ancient world, anatomical knowledge was not at a high level. It is possible that the meridians are just a map used to explain the Meridian Theory in an easy and accessible way for the practitioners of that time.

From a modern point of view, the Meridian System is very similar to the Autonomic Nervous System (ANS). ANS is a self-acting system triggered by signals indicating the relevant needs of the body. ANS consists of two opposing subsystems - sympathetic and parasympathetic, "yin and yang" of the nervous system. The sympathetic nervous system is located in a separate trunk, which is very similar in topographic position of the main meridian. The parasympathetic nervous system is located in parts of the spinal cord, as is the nervous section of the PVS. Of course, the ANS has its anatomical centers and nerves, which prevents the analogy from being so striking. On the other hand, explaining the topography and operation of the ANS is as difficult as explaining the Meridian Theory in antiquity.

There may be another explanation for the passage of the liquid polymer in different ways than those of the meridians. In their studies, mainly Chinese scientists introduced fascial anatomy as a novelty in explaining the morphology of organisms and as a pretension to be the anatomical basis of the Meridian System [62,80-82]. Upon closer inspection of preparations of the polymer, we noticed that they pass through the fascia and the adipose tissue that accompanies them and thus they reach the organs. Unfortunately, I did not have the opportunity to study the matter with Scanning Electron Microscopy (SEM) the found pathways along which the polymer spreads and thus to have more reason to call channels, vessels, or something else what I could find. In fact, from the acupuncture points to the organs, there are different layers of connective and adipose tissue, which leads to a continuous path from the external signal (polymer injection place) to the target organ. It is possible for external and internal signals to pass, just like the polymer, through fascia and aponeurosis, through the parietal pleura and parietal peritoneum to the visceral pleura and visceral peritoneum, and so to the surface and capsule of the organs. Only the established fact of the passage of the polymer from the surface of the organ to its interior without leaving a visible trace is puzzling and strange.

Everything described gives me reason to think that PVS is a direct successor to the ancient knowledge of acupuncture and a clear, physically existing anatomical basis of our familiar system of acupuncture points. As for the way in which the signals go from the acupoints to the target organ, I am inclined to accept fasciology as the basis on which the signal is spread, although with some additional clarifications. I consider the connection between acupuncture points, PVS and fasciology to be that leading, complex acting element, which has been missing so far in the explanation of its action and effect in Eastern medicine. The existence of a complex acting element in its entirety can give clear explanations of the inexplicable so far, as well as be studied by objective and repeated scientific methods.

So far, there were three separate elements to explain the ancient Meridian Theory, each of which is insufficient to fully 
protect it. First, there is an ancient meridian system but with a missing anatomical and physically existing basis. Second, the currently available PVS with an existing anatomical basis and physiological characteristics but not coinciding with the meridian pathways of the signal and with unclear central anatomical organs. Third, a newly described anatomy called fasciology claims to be the anatomical basis of the Meridian System, but with some weaknesses, that cannot fully explain the pathways of signals passing.

From our experiments, as well as from my experience so far and the available data published by other scientists and cited here, it can be concluded that the Meridian Theory, PVS and fasciology are parts of the same system of signals perception and impact on parts and/or a group of organs known both from antiquity and now in modern Eastern medicine. The combination of Meridian Theory, PVS theory with fasciology can lead to a point from which to begin a full understanding of the relationship between the external and the internal environment, as well as the possibilities for controlling these interactions. Now is the time, from the heights of modern science, here, now and in the future, to give a new starting point to the ancient knowledge. Only in this way the achievements and applications of the unambiguously existing Meridian system will be protected, already with the anatomical basis of PVS and fasciology.

What does fasciology pretend to be?

As I've wrote, fascial anatomy claims to be the anatomical basis of Meridian theory, based on the fact that fasciae reach every organ. The structure and distribution of the fasciae provides the basis for this pretension. The authors [82] postulated: "Fascia is a viscoelastic tissue which forms an uninterrupted tissue which forms a functional 3-dimentional collagen matrix and surrounds and connects every muscle and organ, forming continuity throughout the body."

I allow myself not to completely agree with the claims of the fascial anatomy.

First. The anatomical connection between the superficial fascia and the deep fascia with the visceral fascia, which is part of the capsule of the organs, is not shown. Second. The connection between the superficial and deep cadaveric fascia with the fascia covering the large body cavities, as well as that of the central nervous system, is not shown. Third. If the signals were to travel along the fascia, as fasciology claims, they (the signals) would be diffusely scattered because the fascia covers as a "case" the muscles, tendons or form specific membranes and/or sac around the organs.

As a distribution, the fasciae cover the subcutaneous tissue and intermuscular spaces as a 3-D network, as well as the large body cavities being innervated by the autonomic nervous system. Fascial anatomy pretends that the fasciae also cover each of the organs.
In fact, there is no anatomical connection between the superficial and deep fascia on the one hand and the fasciae covering large body cavities such as the thoracic, abdominal and pelvic, and organs' capsules on the other hand, nor what is the relationship between superficial and deep fascia with menings of central nervous system organs.

For brevity, I called "muscle" fasciae the superficial and deep cadaveric fascia, and as "visceral" fasciae (visceral fascia) I accept those that cover large body cavities and capsules of organs, while the envelopes of the central nervous system organs (dura mater, arachnoid and pia mater) are menings.

The disadvantage of fascial theory is that it does not show how the signal or "energy" passes in general from the "muscular" fasciae to the "visceral" fascia and meninges. There are some exceptions: for example, some organs are covered with an adventitia that is not a fascia. In meninges layers, the question is how they are connected to the "visceral" fasciae in general on the one hand, and how the signals pass through the meninges themselves on the other hand.

If the connection between the "muscular fasciae" and the meningeal envelopes, respectively to the "visceral" fasciae, is found, only then would be created a completely closed 3-D network, as claimed by the fascial anatomy. To date, no such anatomical connection has been shown. My opinion is that PVS is the most serious candidate for the connection between the meningeal envelopes with the two parts of the fasciae which would explain the passage of the signal/energy from the surface of the skin and subcutaneous tissue through the different parts of the superficial and deep fascia to the fascias covering the large body cavities and from there passing along the serous membranes to each of the organ systems and each organ separately. The connection of the "visceral" and "muscular" fasciae with the meninges takes place through the blood vessels, the envelopes of the peripheral nerves, as well as through the spinal cord's canal and the cavities in the central brain. PVS passes through each of the described pathways, and it is an excellent candidate for an anatomical base connecting the various organs, apparatuses and systems in the body accompanying the fasciae. In my opinion, fascial anatomy contains three elements unrelated each other. On the one hand are the fasciae of the musculoskeletal system, and on the other hand are the capsules of the internal organs, while the situation with the organs of the nervous system remains unexplained. Only vessels and nerves are the morphological structures that pass through all the elements described and not described by the fascial anatomy.

Our studies [27,52] have shown that the connection from acupoints to the target organ exists, although the known meridians are not observed, but rather to use the pathways described in fasciology through collagen fibers and fat cells accompanying fascia, serous membranes, but also the 
adventitia and the envelopes of the peripheral and central nervous systems. The presence of collagen fibers in both PVS and fascia, serous membranes, adventitia, the envelopes of the central and peripheral organs of the nervous system is of particular importance for the ability of external and internal signals to be transmitted at high speed from the place of signal to the responding organ. I find the reason for this in the distribution and structure of collagen [50]. Collagen is the main component of connective tissue. Collagen is an abundant molecule with special properties, and data indicate that it has properties of interference with photon emission emanating from biomolecular sources. This property of collagen to interfere with photon-emitting processes facilitates the possibility of tuning photon emission throughout an organism $[83,84]$, and it is a step towards the hypothesis that metabolism is regulated by a photon field. This supports Soh's hypothesis [49] regarding the PVS as an optical channel of biophoton emission. Biophotons may be the electromagnetic signals that play a key role in the processes of cell development and differentiation. DNA may act as a photon store and coherent radiator. There is a suggestion that spontaneous ultraweak photon emission from cultured cells is mainly involved in the changes in the ploidy number that occur during the proliferative process of cancer cell lines. This hypothetical light propagation function of the PVS may explain the instantaneous effect that often occurs throughout the entire body with the application of needles at acupoints.

We offer a new point of view concerning the type of vital energy Qi is [51]. Because the PVS may be an optical channel for photon emission, an electromagnetic field that travels throughout the PVS and throughout the DNA in the PVS maybe the mysterious vital energy Qi that can be distributed throughout the entire body. Based on a previous hypothesis, we believe the function of the PVS as an optical channel is closely related to the DNA in the PVS. We hypothesize that DNA carries genetic information, and its structure is capable of storing information obtained from environmental physical fields such as electromagnetic fields.

We support the previous hypothesis that Qi is an electromagnetic standing wave. We can add that these electromagnetic waves may be transformed into information and that this information is stored in the DNA granules of the PVS.

A support for this idea is that physicists recently offered the possibility of converting information to energy; they presented their findings as a spiral-staircase. Toybe and co-authors [85] suggested a new principle for converting information into energy, which was based on Szilard's idea of equivalence between energy and information. Because the bases of DNA lie horizontally between two spiraling strands, the most important model of a biological molecule of DNA is a spiral model, which needs more attention concerning the conversion of information into energy and vice versa through the participation of light. The theoretical physicist Stephen Hawking once said, "electromagnetism is the basis for life itself". To this statement, it can be added that the PVS has all the characteristics necessary to provide electromagnetic waves to every part of the body. The ancient vital energy Qi probably is an electromagnetic wave that is transported through the PVS, and the information obtained from that electromagnetic wave may be stored in the DNA of the PVS microcells (sanals). DNA may produce low-frequency collective motion. Lowfrequency collective motion in DNA refers to the application of statistical thermodynamics to understand lowfrequency vibrations in biomolecules. To solve the perplexing freeenergy deficit problem in protein binding, Chou and Chen [86] suggested the concept of low-frequency phonons in proteins. The phonons have a modified relation between wavelength and energy and are able to transfer energy. The combination of all DNA characteristics makes DNA a powerful candidate that serves as a store for transforming electromagnetic energy information.

We may conclude that the PVS allows communication between living organisms and the environment. The PVS is duplicated by the vascular and the nervous systems during the very early stage of body development. For this reason, the PVS combines the features of the vascular, nervous, immune, and hormonal systems. The PVS in all its aspects is understood as a system that covers the entire body and regulates and coordinates all biological life processes. The PVS receives external and internal signals. The external signals come from the environment as electromagnetic waves. The internal signals are products of metabolic processes and arise as bioelectrical, bioluminous, and acoustical fields. These fields all bring information to the PVS concerning bioprocesses in the body.

Many different oddities in the present of PVS. Doubts, denial, "forgetting". On the other hand, constant and systematic work, indisputable evidence, substantiated theories. Despite the differences and controversies, I do believe that the science of PVS will have a bright future.

\section{PVS AFTER THE FUTURE OR SOME CONCLUSIONS AND PROPOSALS}

What lies ahead for all who study and interpret the basic features of PVS?

In the near future it is inevitable to continue trying to prove by current scientific methodologies the existence and functioning of PVS in all parts of the body in humans and animals, in all Animal Classes, including Vertebrata and 
Invertebrates.

As I have already noted, current methods in science with their limits are not able to fully describe the features of PVS based entirely on the current philosophy of biomedicine with the main pillar of biochemistry, molecular biology and Newtonian physics. Of course, the current achievements in the biological sciences cannot be ignored but they should be supplemented with modern knowledge from other sciences and mainly with the achievements of modern Quantum Biology and Quantum Physics. Quantum biology, Quantum Physics [72,87-89] and Information Medicine [90-92] are currently becoming increasingly important in the biomedical sciences.

Looking at PVS from their point of view, some of the ancient and current knowledge acquires clearer contours. When we discuss processes in organisms that take place at the ultramicroscopic level, we should know that Newton's laws do not work in them, and Quantum Physics is in force, which has led to a new direction - Quantum Biology. Quantum Biology has been known since the 1930s, i.e., almost immediately after the advent of Quantum Mechanics in the early $20^{\text {th }}$ century. Until now, PVS has been studied mainly by biological methods. I think it is time for a new period of research related to PVS, the period of research that uses the methods of Quantum Biology and its derivatives. Traditional biological methods have not been particularly so productive during this 20-year period of PVS research. Of course, it is an indelible success that they proved the existence of PVS at all, as well as finding its main functions. However, the distrust of the "orthodox" scientific elite in the evidence for PVS remains. The transition of research to a second phase, the phase of studying PVS with the methods of Quantum Biology will lead to new discoveries in Information Biology and Information Medicine.

In order to have a basis, I should first clarify the terminology and what I mean by using such terms, because they have existed for a long time. In fact, a form of information medicine has been used since antiquity, because the Meridian Theory itself involves obtaining information, its transfer by specific methods and obtaining a healing effect. The effect was more of a "magic" because the way in which it happens was not understood. The situation is similar with the current rejection of PVS, because the modern world does not believe in "magic", especially scientists. It turned out that the definitively proven phenomena of action of Eastern medicine, and in particular of the Meridian Theory, cannot be explained and understood with the resources of modern biological science based on biochemistry and molecular biology.

It is time for the "magic" to be explained.

My understanding is that with a change in thinking and in the philosophy of understanding Eastern medicine in general, the current division of the scientific community will be overcome. I predict that with the introduction of the methods of Quantum Biology and Quantum Physics and their tool - Information Medicine, it will be explained in an accessible way how the signals determining the disturbance of the internal and external environment are received, how they are transferred to the target tissues and organs and how they affect them.

All ancient cultures and philosophies have tried to explain the world around us and the cosmos by offering a different number of physical elements of which they consist. Together with the physical elements have a non-physical element defined as prana, chi, Reiki, etc. which is denoted as power or force. It is obvious that the mysteries of the world cannot be explained only by the previous achievements of biology, chemistry, and physics.

There is a need for a modern theory about the third element constituting the world - information.

Information is never physical, although it can be presented in various physical forms. The most powerful carrier of information in biology is the DNA molecule. In 2002, the Human Genome Project (HGP) was completed, and it finished with the description of the human gene map. The project's data first astonished their discoverers who initially assumed that man must have at least 150,000 genes. It turned out that man has about 28,700 genes, completely insufficient according to leading scientists to record all the information providing life and life processes. It remains a mystery how the information necessary for life comes and where the rest of it is stored, provided that $96 \%$ of the DNA molecule was previously considered as junk. We can assume that the instructions in the remaining 4\% of the DNA molecule provide the basic vital functions, something like the "factory settings" of the organisms. Where the rest of the information concerning the reception of external and internal signals comes from remains unclear and impossible to explain with current biological thinking.

To explain the "behavior" of information, we should place it within the framework of the other two components defining the world as such - matter and energy. The relationship between energy and matter was described by Einstein [93]. Bremermann states relationship between matter and information [94]. Szilard [98] described the connection between energy and information. The contribution of Einstein, Bremermann and Szilard on the level of atoms imply that matter, energy and information are related. Thus, the Nature consists of matter, energy and information. The available weak electromagnetic fields accompanying each substance can be recorded and their "information copies" can be used [92] instead of the medicines, enzymes, food 
supplements, etc. themselves. It is the "information copies" I mean when I use the term "Information Medicine" but not exactly the known by Austrian healer Erich Körbler and his "New Homeopathy" [96]. His method uses the basics of Chinese medicine, with the aim of harmonizing the electromagnetic fields of the body through the use of geometrical forms. In my interpretation of the term "Information Medicine", I mean that "information copies" can be used in carriers such as water, ointments, and creams. There is already a technology that makes information copies of medicines, vaccines, supplements, etc. which are used in treatment. In the study of PVS, "information copies" can be applied to acupuncture points in the form of injectable and rub solutions by monitoring their effects on target organs. "Information copies" applied in ointments and creams can be used in various techniques of Eastern medicine. The option of using "information copies" deserves attention and should be tested in the study of PVS.

Another possibility for the use of "information medicine", including in PVS, is to strengthen the ability of acupuncture points to perceive and conduct information through the use of new technological methods in the form of small nanoplates attached to acupuncture points. Such technology is already known, and it is reasonable to check its effect in the PVS study.

"The cell knows before it appears."

How do the cell and the whole organism receive information? What are the processes of obtaining and transferring additional "instructions" for organisms other than those that exist in the DNA molecule? The current biological thinking about the morphophysiology of organisms cannot explain some biological phenomena, including the impact of different methods of Eastern medicine.

The Quantum Mechanics where matter has wave-like properties as different physical fields, diffraction, interference electron, proton tunneling etc., probably is able to explain much better these biological phenomena.

Two main questions arise:

1. How does the signal/information penetrate the cells without leaving a trace, without specific channels being available in the cell membrane?

2. How is it possible for the signal/information to be transmitted at high speed and the effect to be almost instantaneous?

The answers are possible if we use Quantum Physics and Quantum Biology:

1. The reception and transmission of the signal/information is instantaneous because it happens through the light electromagnetic quarks - the photons.

2. It penetrates the cell membrane not by active transport, nor by passive, characteristic of the passage of all other molecules, but by quantum tunneling. As an example, quantum tunneling uses enzymes, photosynthesis [8789], etc.

We can speculate that PVS acts as a receptor of external and internal signals/information and transform these signals to target organ(s). External signals are electromagnetic waves as photons and internal signals come from the cells and provide acoustic information which is due to their metabolism. Probably the famous energy "Qi" is information flow which path is PVS.

As the Western medicine is basically biochemical and Eastern medicine is physical, the question is: What would be the new paradigm in medicine!? In my opinion, Quantum Biology and Information Medicine is the new challenge facing humanity. While the chemical formula is the passport of the substance in the field of chemistry, the information copy of the substance is its passport in the field of physics. All substances, objects, biological objects generate a weak electromagnetic field typical for each of them which is a passport of the information.

What is life? We can describe the life in decreasing order as structure, function, molecular biology, organic chemistry, and finally, quantum physics. According to this PVS has all the data to be the main carrier of information. Information Biology can serve as a basis for medicine and biomedical sciences and it should explain the processes that exist for the change of DNA and organisms in general, in accordance with and in response to external causes and internal changes. This response should involve PVS which is the material carrier of the processes that can be explained only by a holistic theory, which means that it treats the organisms as integral and complete biological object. The carriers of the Information and the way of its transmission are both the key to the biological understanding in general, as well as the lock that we have to unlock or break. PVS must be transformed from a science into a technology related to: transmission of external and internal information to organisms; the regeneration of tissues and organs; the treatment of pathological changes and, after all, related the evolution of organisms both in historical terms and in the modern adaptations of organisms to the changing conditions of existence.

Finally, suggestions could be summarized:

1. At the submicroscopic level the laws of quantum physics apply and therefore at this level we should talk about Quantum Biology.

2. Through the Quantum Biology can be explain the perception of the electromagnetic field and photons which are electromagnetic quanta.

3. The photons move at the speed of light from the acupuncture points through the PVS to the target organ(s).

4. By means of quantum tunneling the signal/information 
passes through the cell membrane and has an immediate quantum effect.

5. PVS is receiver and transformer of information.

6. The energy and/or force described in antiquity is in fact the information carried by each object in the form of electromagnetic fields.

Regardless of the thousand-year history of Meridian Theory and Eastern medicine in general, PVS still in its infancy. In its development it has received various names: Kyungrak system, Bonghan System, Primo Vascular System, recently was called HAR-NDS or NDS (Hyaluronic AcidrichNode and Duct System).

Maybe, we should have in mind if the name PROXY ENERGY-INFORMATION SYSTEM is not a better name for PVS nowadays, because of its presumptive function as receiver and transformer of information.

\section{CONFLICT OF INTEREST}

The author declares no conflict of interest.

\section{ORCID}

Miroslav Stefanov, https://orcid.org/0000-0002-3127-6400

\section{REFERENCES}

1. Mann F. A new system of acupuncture. In: Filshie J, Adrian W, eds. Medical Acupuncture: A Western scientific approach. New York: Churchill Livingstone, 1998:464-74.

2. Cai DJ, Chen J, Zhuang Y, Liu ML, Liang FR. Review and comment on the relationship between primo vascular system and meridians. Evid Based Complement Alternat Med 2013; 2013:279176.

3. Litscher G. No, there is no conclusive scientific evidence for visualization of meridians at the moment. J Altern Complement Med 2014;20:215-6.

4. White A, Ernst E. A brief history of acupuncture. Rheumatology (Oxford) 2004;43:662-3.

5. Dorfer L, Moser M, Spindler K, Bahr F, Egarter-Vigl E, Dohr G. 5200-year-old acupuncture in central Europe? Science 1998;282: 242-3.

6. Dorfer L, Moser M, Bahr F, Spindler K, Egarter-Vigl E, Giullén S, et al. A medical report from the stone age? Lancet 1999;354: 1023-5.

7. Potyazhenko MM, Nevoit AV. [Human energy system: evolution of repeated scientific opening]. Ukr Med J 2019;130:139468. Russian.

8. Niboyet J, Mery A. Compte rendu de recherches experimentales sur les meridiens. Actes des III Journ. Intern. d'Acupuncture. 1958:47-51. (in Russian).
9. Kim BH. [Study on the reality of acupuncture meridian]. J Jo Sun Med 1962;9:5-13. (in Korean).

10. Kim BH. [On the Kyungrak system]. J Acad Med Sci, DPR Korea 1963;90:1-41. (in Korean).

11. Kim BH. [The Kyungrak system]. J Jo Sun Med 1965;108:1-38. (in Korean).

12. Kim BH. [Sanal theory]. J Jo Sun Med 1965;108:39-62. (in Korean).

13. Kim MS, Hong JY, Hong S, Lee BC, Nam CH, Woo HJ, et al. Bong-Han corpuscles as possible stem cell niches on the organsurfaces. J Pharmacopunct 2008;11:5-12.

14. Stefanov M. Critical review and comments on B.H. Kim's work on the primo vascular system. J Acupunct Meridian Stud 2012; 5:241-7.

15. Stefanov M, Stoev S, Kim J, Kim S. Western medicine versus Eastern medicine: do both have a common root, scientific background, and worldwide recognition? Altern Ther Health Med 2020;26:38-44.

16. Hajar R. History of medicine timeline. Heart Views 2015;16:43-5. 17. Baik KY, Lee JW, Lee BC, Johng HM, Nam TJ, Sung B, et al. Acupuncture meridian and intravascular Bonghan duct. Key Eng Mater 2005;277-279:125-9.

18. Baik KY, Ogay V, Jeoung SC, Soh KS. Visualization of Bonghan microcells by electron and atomic force microscopy. J Acupunct Meridian Stud 2009;2:124-9.

19. Darras JC, Albarède P, de Vernejoul P. Nuclear medicine investigation of transmission of acupuncture information. Acupunct Med 1993;11:22-8.

20. Han HJ, Sung B, Ogay V, Soh KS. The flow path of alcian blue from the acupoint BL23 to the surface of abdominal organs. J Acupunct Meridian Stud 2009;2:182-9.

21. Han HJ, Ogay V, Park SJ, Lee BC, Kim KW, Lee YW, et al. Primo-vessels as new flow paths for intratesticular injected dye in rats. J Acupunct Meridian Stud 2010;3:81-8.

22. Hossein AM, Yu-Ying T, Tao H, Yu-Qing Z, Yong-Zhe C, WeiBo Z. Finding a novel threadlike structure on the intra-abdominal organ surface of small pigs by using in vivo Trypan blue staining. In: Soh KS, Kang KA, Harrison DK, eds. The Primo Vascular System: Its Role in Cancer and Regeneration. New York: Springer, 2011:63-70.

23. Jia Z, Soh KS, Zhou Q, Dong B, Yu W. Observation of the primo vascular system on the fascia of dogs. In: Soh KS, Kang KA, Harrison DK, eds. The Primo Vascular System: Its Role in Cancer and Regeneration. New York: Springer, 2011:71-6.

24. Jiang X, Kim HK, Shin HS, Lee BC, Choi C, Soh KS, et al. Method for observing intravascular BongHan duct. Korean J Orient Prev Med Soc 2002;6:162-6.

25. Johng HM, Yoo JS, Yoon TJ, Shin HS, Lee BC, Lee C, et al. Use of magnetic nanoparticles to visualize threadlike structures inside lymphatic vessels of rats. Evid Based Complement Alternat Med 2007;4:77-82. 
26. Kim J, Ogay V, Lee BC, Kim MS, Lim I, Woo HJ, et al. Catecholamine-producing novel endocrine organ: Bonghan system. Med Acupunct 2008;20:97-102.

27. Kim J, Stefanov M, Nam MH, Kim S. Tracing Mercox injected at acupuncture points under the protocol of partial body macerations in mice. J Acupunct Meridian Stud 2015;8:314-20.

28. Kwon J, Baik KY, Lee BC, Soh KS, Lee NJ, Kang CJ. Scanning probe microscopy study of microcells from the organ surface Bonghan corpuscle. Appl Phys Lett 2007;90:173903.

29. Lee SY, Lee BC, Soh KS, Jhon GJ. Development of the putative primo vascular system before the formation of vitelline vessels in chick embryos. In: Soh KS, Kang KA, Harrison DK, eds. The Primo Vascular System: Its Role in Cancer and Regeneration. New York: Springer, 2011:77-82.

30. Lee BC, Baik KY, Johng HM, Nam TJ, Lee J, Sung B, et al. Acridine orange staining method to reveal the characteristic features of an intravascular threadlike structure. Anat Rec B New Anat 2004;278:27-30.

31. Lee BC, Yoo JS, Baik KY, Kim KW, Soh KS. Novel threadlike structures (Bonghan ducts) inside lymphatic vessels of rabbits visualized with a Janus Green B staining method. Anat Rec B New Anat 2005;286:1-7.

32. Lee C, Seol SK, Lee BC, Hong YK, Je JH, Soh KS. Alcian blue staining method to visualize Bonghan threads inside large caliber lymphatic vessels and X-ray microtomography to reveal their microchannels. Lymphat Res Biol 2006;4:181-90.

33. Lee BC, Yoo JS, Ogay V, Kim KW, Dobberstein H, Soh KS, et al. Electron microscopic study of novel threadlike structures on the surfaces of mammalian organs. Microsc Res Tech 2007;70:3443.

34. Lee BC, Soh KS. Contrast-enhancing optical method to observe a Bonghan duct floating inside a lymph vessel of a rabbit. Lymphology 2008;41:178-85.

35. Lee SJ, Lee BC, Nam CH, Lee WC, Jhang SU, Park HS, et al. Proteomic analysis for tissues and liquid from Bonghan ducts on rabbit intestinal surfaces. J Acupunct Meridian Stud 2008;1: 97-109.

36. Lee BC, Kim KW, Soh KS. Visualizing the network of Bonghan ducts in the omentum and peritoneum by using Trypan blue. J Acupunct Meridian Stud 2009;2:66-70.

37. Lee BC, Bae KH, Jhon GJ, Soh KS. Bonghan system as mesenchymal stem cell niches and pathways of macrophages in adipose tissues. J Acupunct Meridian Stud 2009;2:79-82.

38. Lee BC, Kim HB, Sung B, Kim KW, Sohn J, Son B, et al. Network of endocardial vessels. Cardiology 2011;118:1-7.

39. Lee BC, Kim HB, Sung B, Kim KW, Sohn J, Son B, et al. Structure of the sinus in the primo vessel inside the bovine cardiac chambers. In: Soh KS, Kang KA, Harrison DK, eds. The Primo Vascular System: Its Role in Cancer and Regeneration. New York: Springer, 2011:57-62.

40. Lim J. Visualization of primo vascular system in brain and spinal cord with fluorescent nano particles [dissertation]. Seoul: Seoul National University; 2011. 86 p.

41. Nam MH, Yin CS, Soh KS, Choi SH. Adult neurogenesis and acupuncture stimulation at ST36. J Acupunct Meridian Stud 2011;4:153-8.

42. Ogay V, Baik KY, Lee BC, Soh KS. Characterization of DNAcontaining granules flowing through the meridian-like system on the internal organs of rabbits. Acupunct Electrother Res 2006;31:13-31.

43. Ogay V, Kim MS, Seok HJ, Choi CJ, Soh KS. Catecholaminestoring cells at acupuncture points of rabbits. J Acupunct Meridian Stud 2008;1:83-90.

44. Park SH. Bioelectrical study of Bonghan system [dissertation]. Seoul: Seoul National University; 2009. 92 p.

45. Shin HS, Johng HM, Lee BC, Cho SI, Soh KS, Baik KY, et al. Feulgen reaction study of novel threadlike structures (Bonghan ducts) on the surfaces of mammalian organs. Anat Rec B New Anat 2005;284:35-40.

46. Soh KS, Hong S, Hong JY, Lee BC, Yoo JS. Immunohistochemical characterization of intravascular Bonghan duct. Microcirculation 2006;13:166.

47. Soh KS. Bonghan circulatory system as an extension of acupuncture meridians. J Acupunct Meridian Stud 2009;2:93-106.

48. Soh KS. Current state of research on the primo vascular system. In: Soh KS, Kang KA, Harrison DK, eds. The Primo Vascular System: Its Role in Cancer and Regeneration. New York: Springer, 2011:25-40.

49. Soh KS. Bonghan duct and acupuncture meridian as optical channel of biophoton. J Korean Phys Soc 2004;45:1196-8.

50. Stefanov M, Kim J. Primo vascular system as a new morphofunctional integrated system. J Acupunct Meridian Stud 2012;5: 193-200.

51. Stefanov M, Potroz M, Kim J, Lim J, Cha R, Nam MH. The primo vascular system as a new anatomical system. J Acupunct Meridian Stud 2013;6:331-8.

52. Stefanov M, Kim JD, Nam MH, Soh KS. New approach of corrosion casting using direct injection of Mercox into the parenchyma of different organs. Anat Rec (Hoboken) 2013;296:724-5.

53. Stefanov M, Kim J. Visualizing the peripheral primo vascular system in mice skin by using the polymer Mercox. J Pharmacopuncture 2015;18:75-9.

54. Sung B, Kim MS, Lee BC, Yoo JS, Lee SH, Kim YJ, et al. Measurement of flow speed in the channels of novel threadlike structures on the surfaces of mammalian organs. Naturwissenschaften 2008;95:117-24.

55. Sung B, Kim MS, Lee BC, Ahn SH, Hwang SY, Soh KS. A cytological observation of the fluid in the primo-nodes and vessels on the surfaces of mammalian internal organs. Biologia (Bratisl) 2010;65:914-8.

56. Vodyanoy V. Characterization of primo nodes and vessels by high resolution light microscopy. In: Soh KS, Kang KA, Har- 
rison DK, eds. The Primo Vascular System: Its Role in Cancer and Regeneration. New York: Springer, 2011:83-94.

57. Yoo JS, Choi K, Baik KY, Chung DS, Soh KS. Liquid-phase microextraction method in capillary electrophoresis to detect adrenaline in Bonghan liquid. J Int Soc Life lnf Sci 2005;23:292-6.

58. Yoo JS, Johng HM, Yoon TJ, Shin HS, Lee BC, Lee C, et al. In vivo fluorescence imaging of threadlike tissues (Bonghan ducts) inside lymphatic vessels with nanoparticles. Curr Appl Phys 2007;7:342-8.

59. Yoo JS, Kim MS, Sung B, Lee BC, Soh KS, Lee SH, et al. Cribriform structure with channels in the acupuncture meridian like system on the organ surfaces of rabbits. Acupunct Electrother Res 2007;32:130-2.

60. Yoo JS, Ayati MH, Kim HB, Zhang WB, Soh KS. Characterization of the primo-vascular system in the abdominal cavity of lung cancer mouse model and its differences from the lymphatic system. PLoS One 2010;5:e9940.

61. Aucamp J, Bronkhorst AJ, Peters DL, Van Dyk HC, Van der Westhuizen FH, Pretorius PJ. Kinetic analysis, size profiling, and bioenergetic association of DNA released by selected cell lines in vitro. Cell Mol Life Sci 2017;74:2689-707.

62. Lim CJ, Lee SY, Ryu PD. Identification of primo-vascular system in abdominal subcutaneous tissue layer of rats. Evid Based Complement Alternat Med 2015;2015:751937.

63. Chikly B, Roberts P, Quaghebeur J. Primo vascular system: a unique biological system shifting a medical paradigm. J Am Osteopath Assoc 2016;116:12-21. Erratum in: J Am Osteopath Assoc 2016;116:201.

64. Ping A, Zhendong S, Rongmei Q, Jingxing D, Wei C, Zhongyin $Z$, et al. Primo vascular system: an endothelial-to-mesenchymal potential transitional tissue involved in gastric cancer metastasis. Evid Based Complement Alternat Med 2015;2015: 812354.

65. Adstrum S, Nicholson H. A history of fascia. Clin Anat 2019;32: $862-70$.

66. Chen PH, Tai CJ, Chien LY, Lai JCY, Huang SM, Chen YH. Application of propensity scores to estimate the association between cardiovascular disease and meridian energy. Eur J Integr Med 2016;8:198-203.

67. Akramo Sadat A, Fatemeh N, Fatemeh E, Laila S, Hoorie Mohammadi K, Mohammad Hossein A. Persian medicine nonpharmacological therapies for headache: phlebotomy and wet cupping. J Tradit Chin Med 2018;38:457-64.

68. Wang Z, Zhang W, Jia S, Tian Y, Wang G, Li H. Finding blue tracks in Gephyrocharax melanocheir fish similar to the locations of acupuncture meridians after injecting Alcian blue. J Acupunct Meridian Stud 2015;8:307-13.

69. Ghiron C. The primo vascular system as a possible exosomal route across the body: implications for tumor proliferation and metastasis. J Acupunct Meridian Stud 2019;12:25-8.

70. Lee HS, Kang DI, Yoon SZ, Ryu YH, Lee I, Kim HG, et al.
Evidence for novel age-dependent network structures as a putative primo vascular network in the dura mater of the rat brain. Neural Regen Res 2015;10:1101-6.

71. Brito LS, Maggitti Junior LDP, Ferraz PA, Vasconcelos IC, Carvalho JVGDS, Loiola MVG, et al. Effects of equine chorionic gonadotropin administered via the Baihui acupoint on follicular ovarian dynamics and the luteal function of cattle during an ovulation synchronization treatment regimen for fixed-time artificial insemination. Anim Reprod Sci 2020;223:106631.

72. Gomes LR, Leão P. Recent approaches on signal transduction and transmission in acupuncture: a biophysical overview for medical sciences. J Acupunct Meridian Stud 2020;13:1-11.

73. Yonghong S, Ruizhi W, Yue Z, Xuebing B, Tarique I, Chunhua $\mathrm{L}$, et al. Telocytes in different organs of vertebrates: potential essence cells of the meridian in Chinese traditional medicine. Microsc Microanal 2020;26:575-88.

74. McDonald MJ. Will the primo vascular system finally solve the mystery of acupuncture? Med Acupunct 2015;27:33-7.

75. Samartín AP. [The Qi pathways]. Rev Int Acupunt 2013;7:16-8. (in Spanish).

76. Park ES, Kim HY, Youn DH. The primo vascular structures alongside nervous system: its discovery and functional limitation. Evid Based Complement Alternat Med 2013;2013:538350.

77. Lee BC, Yoon JW, Park SH, Yoon SZ. Toward a theory of the primo vascular system: a hypothetical circulatory system at the subcellular level. Evid Based Complement Alternat Med 2013; 2013:961957.

78. Mondy WL, Casteleyn C, Loo DV, Raja M, Singleton C, Jacot JG. Osmium tetroxide labeling of (poly)methyl methacrylate corrosion casts for enhancement of micro-CT microvascular imaging. Microsc Microanal 2013;19:1416-27.

79. Casteleyn C, Cornillie P, Van Ginneken C, Simoens P, Van Cruchten S, Vandevelde K, et al. Lymph drainage from the ovine tonsils: an anatomical study of the tonsillar lymph vessels. Anat Histol Embryol 2014;43:482-9

80. Bai Y, Yuan L, Soh KS, Lee BC, Huang Y, Wang CL, et al. Possible applications for fascial anatomy and fasciaology in traditional Chinese medicine. J Acupunct Meridian Stud 2010;3: 125-32.

81. Bai Y, Wang J, Wu JP, Dai JX, Sha O, Tai Wai Yew D, et al. Review of evidence suggesting that the fascia network could be the anatomical basis for acupoints and meridians in the human body. Evid Based Complement Alternat Med 2011;2011:260510.

82. Yang C, Du YK, Wu JB, Wang J, Luan P, Yang QL, et al. Fascia and primo vascular system. Evid Based Complement Alternat Med 2015;2015:303769.

83. Wijk RV, Wijk EP. An introduction to human biophoton emission. Forsch Komplementarmed Klass Naturheilkd 2005;12:7783.

84. Wijk E, Groeneveld M, Greef J, Wijk R. Unusual optical properties of collagen and implications for the primo vascular 
system. In: Soh KS, Kang KA, Harrison DK, eds. The Primo Vascular System: Its Role in Cancer and Regeneration. New York: Springer, 2011:235-41.

85. Toyabe S, Sagawa T, Ueda M, Muneyuki E, Sano M. Experimental demonstration of information-to-energy conversion and validation of the generalized Jarzynski equality. Nat Phys 2010; 6:988-92.

86. Chou KC, Chen NY. The biological functions of low-frequency phonons. Sci Sin 1977;20:447-57.

87. Kim Y, Bertagna F, D’Souza EM, Heyes DJ, Johannissen LO, Nery ET, et al. Quantum biology: an update and perspective. Quantum Rep 2021;3:80-126.

88. McFadden J, Al-Khalili J. The origins of quantum biology. Proc Math Phys Eng Sci 2018;474:20180674.

89. Al-Khalili J. Overview of the quantum biology session at the 19th IUPAB congress and 11th EBSA congress. Biophys Rev 2017;9:293-4.

90. Teymurazovna S. [Experimental - clinical evaluation of the effects of the application bioresonance technologies in cardiac surgery patients in early postoperative period] [dissertation].
Moscow: Bakulev Scientific Center for Cardiovascular Surgery; 2014. Russian.

91. Gotovskiy MY. [Bioresonance means of individual therapy: biological and therapeutic mechanisms of action]. Tradic Med 2018;1:4-12. Russian.

92. Gotovskiy MY, ed. Anokhin's theory of functional systems is the language of information medicine. 25th International Conference: Theoretical and Clinical Aspects of Application of Bioresonance and Multiresonance Therapy, April 5-6, 2019, Moscow, Russia. Moscow: IMEDIS, 2019.

93. Baierlein R. Does nature convert mass into energy? Am J Phys 2007;75:320-5.

94. Anderson RW, Conrad M. Hans J. Bremermann: a pioneer in mathematical biology. Biosystems 1995;34:1-10.

95. Szilard L. [On the decrease of entropy in thermodynamic system by intervention of intelligent beings]. Z Phys 1929;53:840-56. German.

96. Sagi M. The new homeopathy: a new paradigm in information medicine. World Futures 2016;72:53-68. 